\section{MINERÍA NEOLÍTICA EN GAVÁ (BAIX LLOBREGAT, BARCELONA)}

\author{
NEOLITHIC MINING AT GAVÀ \\ (BAIX LLOBREGAT, BARCELONA)
}

\author{
JOSEP BOSCH ARGILAG ÓS (*) \\ ALICIA ESTRADA MARTÍN $(*)$ \\ MARÍA JOSÉ NOAIN MAURA (**)
}

\section{RESUMEN}

A partir de los resultados de la excavación arqueológica, del estudio geológico y de la experimentación se plantean los procesos del trabajo minero y de la variscita durante el Neolítico Antiguo Evolucionado y el Neolítico Medio en Gavá. Se analizan: las estructuras de explotación, con diferencias formales y de distribución entre un período y otro; los utensilios mineros, con variaciones materiales, formales y funcionales; los productos extraídos, identificándose únicamente la variscita; la elaboración de cuentas de variscita realizada en el mismo yacimiento; el contexto económico y social de estos procesos de trabajo, no aceptando una especialización de las comunidades neolíticas de Gavá en la minería y en la elaboración de cuentas; y los aspectos ideológicos ligados a la minería, proponiendo una unión con los de la agricultura y la ganadería.

\section{ABSTRACT}

The process of mining and variscite obtention in Gavà during the Developed Early Neolithic and the Middle Neolithic have been studied regarding the results

(*) Museo de Gavá. Plaza Dolors Clua, 13-14. 08850 Gavá. Barcelona. Tel.: (93) 63825 70. Fax: (93) 6383596.

(*) Universidad Autónoma de Madrid. Facultad de Filosofía y Letras. Departamento de Prehistoria. Carretera de Colmenar, Km. 15. 28049 Cantoblanco. Madrid.

El artículo fue remitido en su versión final el 13-III-96. of archaeological excavations, the geological study and experimentation. The following issues have been analysed: the exploitation structures, with differences in shape and distribution between both periods; the mining tools with differences in materials, shapes and use; the products obtained, among which only variscite can be identified; the manufacturing of variscite beads near the mine; the economic and social context of these work processes, not eccepting specialization among Gavà Neolithic communities in mining and bead manufacturing; and the ideological trends related to mining proposing a union with those of agriculture and cattle.

Palabras clave: Neolítico Antiguo Evolucionado. Neolítico Medio. Cultura de los Sepulcros de Fosa. Minería.Variscita. Minas Prehistóricas de Gavá. Can Tintorer. Ornamentos corporales.

Key words: Developed Early Neolithic. Middle Neolithic. Culture of Pit Graves. Mining. Variscite. Gavà Prehistoric Mines. Can Tintorer. Body ornaments.

\section{INTRODUCCIÓN (J.B.A. y A.E.M.)}

En este artículo planteamos un estado de la cuestión sobre los procesos del trabajo minero y del producto obtenido durante el Neolítico en Gavá. Nos referimos a la morfología, distribución y contexto geológico de las estructuras excavadas, su variación en el tiempo, el producto 
extraído, los objetos manufacturados con él, el instrumental minero y de elaboración de estos objetos, así como al contexto económico, social e ideológico en el que se produjeron dichos procesos de trabajo. Las fuentes utilizadas son los resultados de la excavación arqueológica en el yacimiento de las Minas Prehistóricas de Gavá, el estudio y cartografía geológica del mismo, y la experimentación arqueológica sobre la minería neolítica.

Las excavaciones del Museo de Gavá en las Minas Prehistóricas de Can Tintorer se iniciaron el año 1991 y desde entonces se han continuado hasta la actualidad, alternándolas con períodos de estudio y de trabajos de conservación. Las excavaciones se han practicado al aire libre, con el objetivo de localizar posibles restos en superficie (hábitat, necrópolis, etc.), y en los rellenos del interior de algunas de las minas neolíticas. $\mathrm{Al}$ aire libre, los resultados han sido prácticamente nulos, ya que no se han localizado restos arqueológicos contemporáneos a la explotación de las minas. De haber existido restos del Neolítico en superficie, éstos habrían desaparecido por diversos motivos. Sí han sido positivos, en cambio, los resultados de las excavaciones del relleno de las minas 5, 11, 16, 42, 68 y 70.

$\mathrm{El}$ estudio geológico ha sido realizado por $\mathrm{J}$. C. Melgarejo, F. Costa y A. Camprubí de la Facultad de Geología de la Universidad de Barcelona, seleccionando tres de las minas en un estado de excavación más avanzado (1/2, 8 y 5/11) (Costa et alii, 1994). Su objetivo era elaborar una cartografía geológica del interior de las minas, en la que poder ver qué unidades geológicas siguen e intentar establecer así los recursos explotados. Asimismo, la disposición de las estructuras mineras sobre la geología podía revelar datos acerca de cómo plantearon los mineros del Neolítico la explotación y, adicionalmente, una aproximación a sus conocimientos de geología.

La experimentación arqueológica pretende validar las hipótesis formuladas sobre los diferentes aspectos del proceso de trabajo minero, y consiste en la excavación de una estructura subterránea de extracción de mineral similar a las neolíticas, siguiendo los procedimientos técnicos del Neolítico. Los objetivos son diversos: comprender a través de la práctica los modos de excavación, la funcionalidad de los instru-

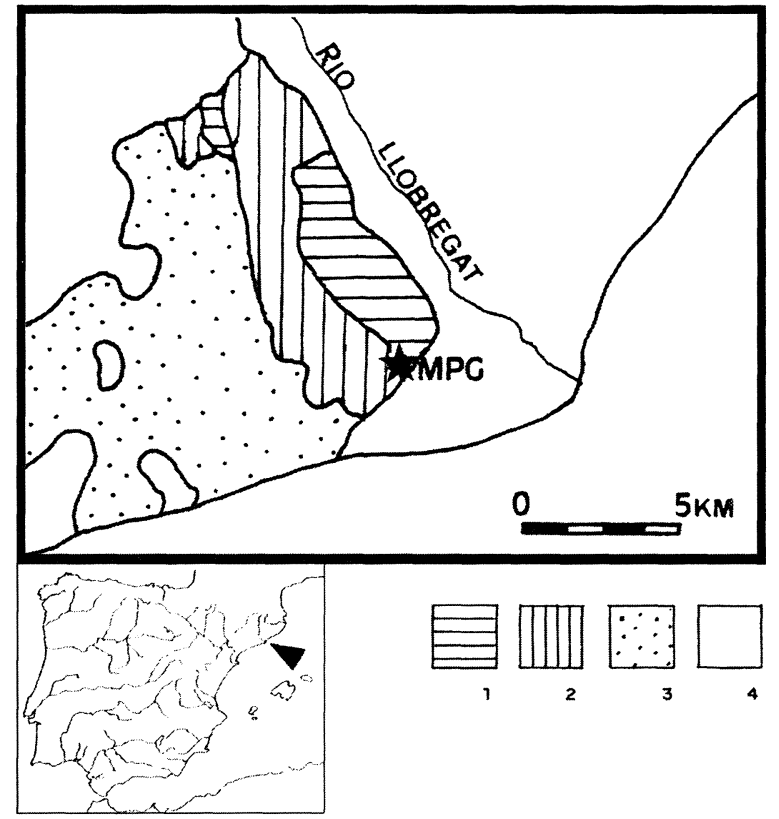

Fig. 1. Localización de las Minas Prehistóricas de Gavá y mapa geológico de la zona del Noroeste del macizo del Garraf y de la desembocadura del río Llobregat:

1. Paleozoico.

2. Triásico.

3. Cretácico-Jurásico

4. Cuaternario.

* Minas Prehistóricas de Gavá.

mentos que nos aparecen en el relleno de las minas, conocer el volumen de materia prima extraído, los sistemas de selección del mineral, el número necesario de trabajadores, el tiempo utilizado para la excavación de una longitud de mina dada, poner en práctica los posibles sistemas de iluminación, etc.

\section{MARCO GEOGRÁFICO DEL YACIMIENTO}

Las Minas Prehistóricas de Gavá se encuentran en el extremo meridional del llano de Barcelona, planicie de casi $170 \mathrm{~km} 2$ de superficie situada en el centro del litoral catalán (Fig. 1). Éste está constituido por formaciones cuaternarias y se extiende desde el mar hasta la Cordillera Litoral, la cual adquiere alturas de hasta 500 m.s.n.m. y lo delimita por el Noreste, Oeste y Suroeste. Al Este y Sureste está bañado por el

T. P., 53, n. ${ }^{\circ} 1,1996$ 
Mediterráneo. El río Llobregat, que atraviesa dicha Cordillera, separa el macizo del Garraf, al Sur, de la sierra de Collserola, al Norte, y desemboca en el mar en el Sur del llano de Barcelona, donde ha formado su delta. La zona de las Minas Prehistóricas de Gavá está situada en la margen derecha de la desembocadura de dicho río, al pie de la vertiente oriental del macizo del Garraf. Dicha vertiente se caracteriza geológicamente por la presencia escalonada, en dirección SO-NE, de materiales del Cretácico-Jurásico, los más elevados; del Trías, donde las pendientes asumen los máximos valores y son frecuentes grandes escarpados; del Paleozoico, rocas que han estado expuestas mucho tiempo a la acción de agentes externos y que presentan topografías suaves y onduladas; a éste le suceden terrenos cuaternarios con muy poco declive.

Las minas de época neolítica conocidas hasta el momento están concentradas en el extremo SE de la franja formada por el zócalo paleozoico que aflora en el extremo NE del Macizo del Garraf, concretamente en el sector del mismo conocido como cerro de Can Tintorer. Aislado del resto, está rodeado por sedimentos cuaternarios por todos los lados excepto por el Oeste, donde se une a la citada franja paleozoica.

\section{MARCO CRONOLÓGICO}

Las Minas Prehistóricas de Gavá fueron explotadas ininterrumpidamente durante dos períodos del Neolítico: el Neolítico Antiguo Evolucionado y el Neolítico Medio.

Por un lado, las cerámicas de las minas 42 , 68 y 70 muestran afinidades con el llamado Neolítico Antiguo Evolucionado Postcardial o Molinot, bien representado en la comarca vecina del Penedés (Mestres, 1981), que corresponde al horizonte neolítico de las cerámicas peinadas. Son características de este grupo las formas simples, pastas poco depuradas, superficies más o menos alisadas, junto a un número significativo de peinadas, con abundantes y variados elementos de prensión y decoradas con cordones lisos y nervaduras.

Por otro lado, las cerámicas procedentes de otras minas muestran afinidades con yacimien-

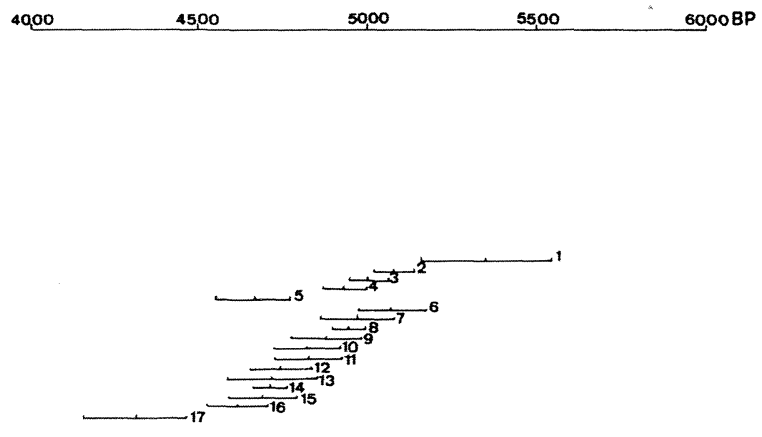

Fig. 2. Tabla con dataciones C14 (no calibradas) del yacimiento de las Minas Prehistóricas de Gavá: 1-5: Neolítico Antiguo Evolucionado; 6-17: Neolítico Medio (1 y 6-17 Villalba et alii, 1986: 57; Blasco et alii, 1992: 219; 2-5: Bosch y Estrada, 1995: 255).

tos del Neolítico Medio correspondientes a la Cultura de los Sepulcros de Fosa. En general, presentan una calidad técnica superior a las de la etapa anterior, con superficies lisas, acabado bruñido cuidado y coloración oscura, en algunos casos se decoran con esgrafiado. Es importante la representación de las formas compuestas (Ripoll y Llongueras, 1963; Muñoz, 1965; Llongueras et alii, 1981).

En la figura 2 podemos comprobar cómo las dataciones correspondientes a los materiales del Neolítico Postcardial oscilan entre el 3350 y el 2950 a.C. (no cal.). Por el contrario, el mayor número de dataciones asociadas a materiales del Neolítico Medio se sitúan desde el 2950 hasta el 2550 a.C. Según esto, la explotación del Neolítico Postcardial en Gavá está datada en la segunda mitad del IV milenio a.C., mientras que la del Neolítico Medio en la primera mitad del III milenio a.C. Las fechas absolutas obtenidas para el Neolítico Antiguo Evolucionado Postcardial en Gavá, nos llevan a prolongar esta fase hasta finales del IV milenio, por lo que quizás su denominación resulte más apropiada como Neolítico Antiguo Evolucionado.

Distinto es el problema planteado por las cerámicas consideradas de estilo epicardial por su decoración incisa y/o impresa. Estas no aparecen en conjuntos aislados, sino mezcladas con materiales de otras épocas: Neolítico Antiguo Evolucionado y Edad del Hierro. Es posible que explotaciones mineras de estos períodos destruyeran estructuras mineras o de hábitat neolíticas epicardiales. No hay que descartar, 
sin embargo, que las decoraciones incisas e impresas sean una perduración del Neolítico Antiguo Epicardial durante el Neolítico Antiguo Evolucionado. No puede, pues, reconocerse una fase epicardial.

\section{TRABAJO MINERO}

\subsection{Las minas}

Durante el Neolítico, los sistemas de obtención de materias primas líticas en Gavá fueron siempre subterráneos, es decir en estructuras mineras desarrolladas en profundidad de forma más o menos extensa y en condiciones de ausencia total o parcial de luz solar. Puede sorprender, dada la poca profundidad de algunas de las minas, que en ningún caso se optase por una explotación en cantera, más segura que la subterránea. Quizás la explicación esté en la mayor rentabilidad de esta última respecto a la efectuada a cielo abierto, al restringir el volumen de estériles.

La distribución y la morfología de las estructuras de extracción parecen haber estado condicionadas por la geología de la zona. En ella aflora el Paleozoico (Silúrico y Devónico), representado por pizarras alumínicas sericíticas grises que alternan con calizas y dolomías. La orogenia hercínica produjo dos grupos de pliegues coaxiales, de ejes aproximadamente NO$\mathrm{SE}$, con una primera generación de vergencia $\mathrm{NE}$ y otra SO. En la esquistosidad predomina la dirección NE-SO, estando sus capas fuertemente inclinadas hacia el $\mathrm{S}$, en ocasiones llegando a la verticalidad. Estos materiales están recubiertos discordantemente por otros del Cuaternario (caliche y arcilla).

Los minerales que fueron explotados durante el Neolítico se encuentran dentro de las pizarras. En ellas se han reconocido dos tipos fundamentales de mineralizaciones de fosfatos: una estratiforme con niveles monominerálicos de estrengita, variscita y apatito y otra en vetas de variscita, sobre todo, pero también de estrengita y fosfosiderita, a los que se asocian alunita y jarosita. Cabe destacar, asimismo, la presencia tanto de niveles con grandes nódulos de chert (ópalo) como monominerálicos de hematites. Todas estas mineralizaciones son concordantes con la esquistosidad (Mata et alii, 1983; Camprubí et alii, 1994; Costa et alii, 1994).

Dos aspectos de la geología de la zona parecen haber influido claramente sobre la forma como se realizó la explotación minera durante el Neolítico: la dirección NE-SO de la esquistosidad y la fuerte inclinación tanto de las capas de pizarra como de los estratos minerales.

\section{Neolítico Antiguo Evolucionado}

Las estructuras mineras del Neolítico Antiguo Evolucionado muestran una implantación lineal, de acuerdo con la orientación de la esquistosidad NE-SO, a poca distancia de la divisoria entre las dos vertientes principales ( $\mathrm{N}$ y S) del cerro de Can Tintorer, siempre en la expuesta al Sur. En sus cotas más elevadas la cubierta cuaternaria debía ser más débil pudiendo aflorar en algun sector las pizarras.

La morfología completa de las minas de este período, hasta el momento sólo ha podido ser estudiada en la número 70 , la única íntegramente excavada. La forman una galería, estrecha, alargada y poco inclinada, y un único pozo de acceso, de muy reducidas dimensiones. El pozo es elíptico con una profundidad de $140 \mathrm{~cm}$. y una abertura máxima de $110 \mathrm{~cm}$. Se abre paso a través de una débil capa de arcilla y de caliche hasta la pizarra, donde comunica con una galería rectilínea de sección más o menos circular excavada en dirección Sur-Norte, tiene unos $5 \mathrm{~m}$. de largo y $110 \mathrm{~cm}$. de diámetro, con un recorrido semihorizontal que va formando escalones. Con esta longitud, bien por interrupción del mineral o bien por limitaciones técnicas, fue abañdonada y debió buscarse el mismo banco de mineral algunos metros al Este o al Oeste con una nueva estructura, sin establecerse una comunicación interna entre las diferentes minas.

Si bien estas minas dan una impresión de simplicidad y de rudimentaria eficacia, la observación de su estructura y distribución revela una comprensión de la geología del terreno por parte de los mineros neolíticos (noción de estratigrafía litológica, inclinación de las capas de roca y mineral y orientación de la esquistosi-

T. P., 53, n. ${ }^{\circ} 1,1996$ 
dad), asimismo revela su habilidad en repartir las cargas de los terrenos superiores a las galerías mediante la configuración del techo en bóveda de cañón.

\section{Neolítico Medio}

En el Neolítico Medio las estructuras mineras son más numerosas que en la etapa anterior, alcanzan mayor profundidad y extensión, ahora ya en zonas donde una potente capa de caliche y arcilla oculta por completo las pizarras. Como las del Neolítico Antiguo Evolucionado se sitúan en la vertiente Sur del cerro de Can Tintorer y siguen la orientación NESO de los esquistos que se refleja en la implantación lineal de los accesos a las estructuras subterráneas y en la morfología general de éstas.

Las estructuras son extremadamente más complejas que las anteriores y, a diferencia de éstas, difíciles de aislar unas de otras. Analizando el conjunto de las estructuras subterráneas del Neolítico Medio conocidas se puede observar cómo forman largas franjas paralelas de cavidades discontinuas e irregulares, a modo de hormiguero, que siguen la orientación de la esquistosidad y de la mineralización estratoligada. El acceso desde el exterior se realiza mediante pozos semiverticales, que pueden alcanzar los $10 \mathrm{~m}$ de profundidad, que atraviesan la capa de arcillas y de caliche, hasta llegar a las pizarras. Estos pozos parecen tener una implantación equidistante, siguiendo la alineación citada de los esquistos; de su fondo parte la excavación minera en el interior del nivel geológico de explotación, las pizarras, con formas y dimensiones variables. Se distinguen cámaras, con o sin pilastra, galerías, que conectan estas cámaras entre sí, y pozos interiores, que siguen la orientación de la esquistosidad. Las estructuras, dentro de una misma franja, pueden encontrarse a distintos niveles, formando pisos de explotación. Las franjas explotadas pueden medir unos $5 \mathrm{~m}$. de ancho y llegar hasta 15 de profundidad, desconocemos aún su longitud. A veces, galerías transversales a la orientación de la esquistosidad comunican cámaras de franjas distintas (Fig. 3).

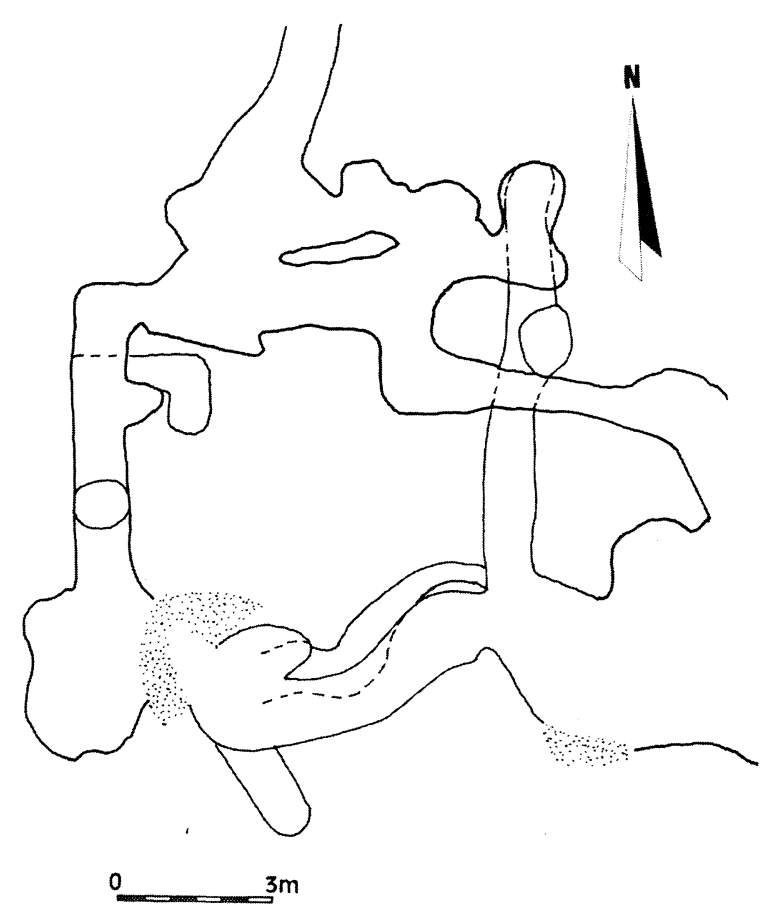

Fig. 3. Planta de un tramo de dos franjas de explotación minera (dirección E-O) conectadas por galerías transversales (N-S). Mina número 8 de las Minas Prehistóricas de Gavá (Baix Llobregat, Barcelona).

La discontinuidad e irregularidad de las cavidades en las franjas explotadas pudo tener varias causas: 1) la mineralización no aparecía de forma continua; 2) el hueco discontinuo hace más segura la estructura al repartir las cargas de los terrenos superiores y laterales, mientras que en las grandes cavidades los desprendimientos serían más frecuentes; y 3) facilitaría los movimientos de los mineros y de los materiales, especialmente en la vertical. Una posible explicación de las galerías transversales es que fueran galerías de prospección que partiendo de una franja de explotación en dirección a un sector no explotado, buscaran una nueva capa rica en mineralización. Esto permitiría saber a que distancia de la franja conocida practicar los pozos de acceso a la nueva. Hay qué tener en cuenta que, si bien buena parte de pozo se excavaba en arcilla, su abertura no dejaba de ser costosa.

Hemos visto cómo con el paso del Neolítico Antiguo Evolucionado al Neolítico Medio, el sistema de explotación se transformó; esto pudo deberse a un mayor conocimiento del 
medio geológico y de la tecnología, quizá promovido por una mayor demanda de los productos extraídos. No sabemos hasta qué punto el paso de las estructuras simples de la primera etapa a las complejas de la segunda fue brusco o gradual. Nos lo impiden varios hechos. En muchas zonas del yacimiento la excavación arqueológica ha sido incompleta y, por otro lado, la larga explotación motivó probablemente que algunas formas estructurales quedasen desfiguradas por las posteriores. Es necesario poner un mayor cuidado en datar los diferentes sectores de las estructuras mineras, antes de poder ensayar una reconstrucción de su desarrollo en el tiempo más precisa.

\subsection{Utensilios mineros}

La actividad minera debió comportar, seguramente, el uso de muchos utensilios, fabricados con materiales diversos, sean de origen orgánico o inorgánico. La documentación arqueológica únicamente nos permite conocer algunos de ellos: instrumentos pesados, como los picos de piedra, y utensilios ligeros, como cinceles de hueso (Lám. I). Los primeros son herramientas dotadas de masa inercial, más o menos consistentes, alargados, de sección circular o elíptica, con una o dos extremidades apuntadas, a veces presentan un encaje o muesca que sugiere su enmangue. Los de hueso son biselados, fabricados sobre metápodos de buey. Un análisis más profundo que aglutinara morfometría, peso, trazas sean de elaboración, reafilado o uso, materias primas y experimentación, muy probablemente nos permitiría diferenciar una mayor variedad de usos: picos más o menos ligeros, azuelas, mazas, cinceles, cuñas, etc.

Instrumentos de trabajo indirectos son los utilizados en la fabricación y reafilado de las herramientas citadas: útiles de rocas abrasivas, para los cinceles de hueso, y percutores esféricos de cuarzo, para los picos de piedra (Lám. I). La Arqueología experimental ha puesto en evidencia la necesidad de una continua fabricación y reparación de los instrumentos de hueso y de piedra. Los percutores de cuarzo pudieron utilizarse, también, para golpear los cinceles de hueso.

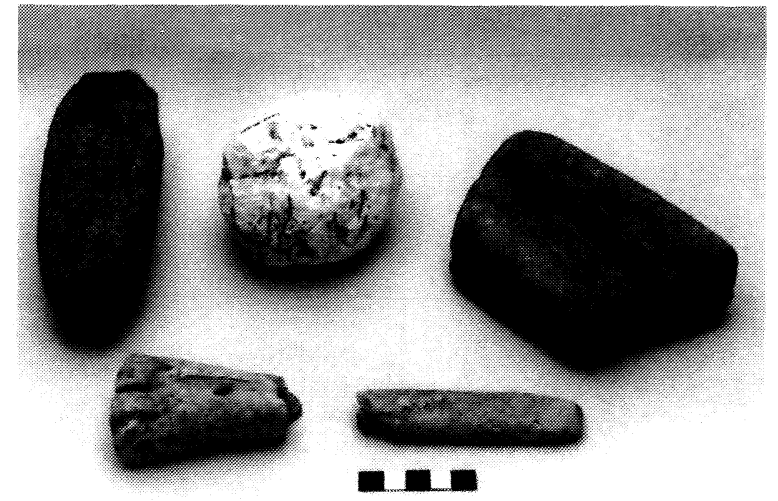

Lám. I. Instrumentos mineros: pico de corneana, cincel de hueso, percutor de cuarzo y pulidor de arenisca de las Minas Prehistóricas de Gavá (Baix Llobregat, Barcelona).

Una parte de los materiales líticos pudo obtenerse en la misma zona de explotación, en el curso de los torrentes de la vertiente Norte del macizo del Garraf que atraviesan terrenos del Triásico y del Paleozoico. Su aprovisionamiento por recolección superficial de material en posición secundaria queda sugerido por algunas piezas que conservan el pulido natural (cantos rodados).

En cambio los picos de minero se elaboraron principalmente de corneana, roca alóctona para la que se propone como lugar de procedencia, dada la proximidad, la vertiente meridional de la sierra de Collserola (Álvarez y Clop, 1994: 244). Los grupos de mineros de Gavá la obtendrían por sí mismos desplazándose hasta dicha sierra, o por intercambio con la comunidad que la explotaba. Si bien la fuente de materia prima propuesta para la corneana se encuentra fuera del área de captación teórica del asentamiento de Gavá (una hora de marcha a su alrededor), la importancia para sus miembros y la proximidad, al hallarse también en el bajo Llobregat, hace que nos inclinemos por una explotación directa, que correspondería al llamado "suministro territorial" (Ramos, 1984: 111).

La experimentación arqueológica nos permite deducir el posible uso de estos instrumentos en el proceso de trabajo minero: para los picos una función de martilleado de la roca provocando en ella fracturas y grietas, para los

T. P., 53, n. ${ }^{\circ} 1,1996$ 
cinceles una de dilatación de estas grietas a partir de las cuales extraer lajas de roca. Nos ha permitido comprobar, también que el calentamiento de la roca con fuego y su enfriamiento brusco con agua, previos al martilleado, pudo ser un método efectivo para facilitar su agrietado y fractura. El registro arqueológico de Gavá, sin embargo, no prueba este tratamiento térmico de la roca, a no ser que interpretemos en este sentido parte de los abundantes restos de madera carbonizada, generalmente de buena calidad combustible, encontrados en niveles de relleno de las minas, y la desforestación de la zona que pone de manifiesto el análisis antracológico para estas épocas (Ros, 1986; 1994: 217). También según la experimentación, durante todo el proceso de trabajo es necesario un frecuente reafilado de las herramientas y la fabricación de otras nuevas. Es conveniente, para no entorpecer el ritmo de trabajo, que un miembro del equipo se ocupe únicamente de estas tareas. Tanto el trabajo del picador como el de fabricación y cuidado de los instrumentos son duros y es necesario efectuar descansos. Así, el número idóneo de obreros es de tres: el picador, el encargado del mantenimiento y un tercero que los releve. De esta forma no se interrumpe el trabajo. A medida que la mina vaya alcanzando mayor profundidad, será necesario ampliar el equipo para la evacuación de estériles al exterior.

\subsection{Iluminación de las estructuras mineras}

La iluminación constituye un problema de gran interés en la reconstrucción del ambiente de trabajo. El corto recorrido de las minas del Neolítico Antiguo Evolucionado (5 m), junto a la exposición Sur de su apertura y la orientación Sur-Norte de su galería, pudo hacer innecesarios los sistemas de iluminación artificial, al menos en las horas centrales del día cuando la luz solar es más intensa. No puede decirse lo mismo de las estructuras del Neolítico Medio, cuya complejidad y profundidad obstaculizan, en cualquier momento del día, la llegada de la luz solar. Buena parte de ellas está permanentemente en la oscuridad, siendo imposible el trabajo sin iluminación artificial.
No contamos con ninguna evidencia arqueológica clara al respecto, como son las cazoletas de piedra de forma y profundidad variables, supuestas lámparas de aceites o grasas conocidas en otras minas neolíticas, como las de la Defensola (Pouïlles-Italia) (Galiberti y Guarascio, 1990: 305, Fig. 4.2). Quizás sean indicio de iluminación artificial, algunos de los abundantes carbones aparecidos entre los rellenos de las minas, especialmente los de madera de Juniperus, según algunos autores, buen combustible para la iluminación y utilizada con este fin en diversas épocas (Olive y Taborin (dir.), 1989: 87).

\subsection{Productos extraídos}

La determinación de las materias líticas extraídas de Gavá dista mucho de ser un tema resuelto. Desde un primer momento se aceptó que una de estas materias era la variscita. Es un mineral del grupo de los fosfatos, dominante entre los objetos de adorno elaborados con el material pétreo de coloración verdosa genéricamente llamado calaíta. Confirmaban el interés durante el Neolítico por la calaíta su amplia distribución en los ajuares de la Cultura de los Sepulcros de Fosa con la que se asociaba la explotación de Gavá, las señales de las herramientas de trabajo minero visibles alrededor de las vetas de variscita y la elaboración de piezas de collar en el mismo yacimiento.

Aceptar que la variscita fue el único material explotado o el objetivo primordial de las minas de Gavá en el Neolítico presentaba problemas, al menos en el momento en que iniciamos nuestros estudios. Dudábamos que un trabajo de tal envergadura se hubiese practicado con el único objetivo de obtener un material con finalidades suntuarias; también nos sorprendía documentar el inicio de la explotación durante el Neolítico Antiguo Postcardial, cuando el apogeo del uso de la variscita parecía producirse en el período posterior (Neolítico Medio). Así pues, un objetivo inicial de nuestra investigación era confirmar o descartar la obtención en Gavá de otros materiales además de la variscita.

Si bien en las paredes de las estructuras subterráneas no se reconocía, había sido pu- 
blicada la existencia de corneana en un afloramiento dentro del mismo contexto geológico y no lejos de los pozos conocidos, sin estar basada su identificación en análisis petrológicos (Villalba et alii, 1986: 19). La corneana fue utilizada para elaborar buena parte del utillaje lítico pulido neolítico en Cataluña (Bosch, 1984; Álvarez, 1993). Sin embargo, las muestras de dicho afloramiento analizadas por A. Álvarez y X. Clop (1994: 234) en lámina delgada, constatan que no es corneana sino cuarcita y cuarcita esquistosa y descartan la explotación de corneana en la zona de Gavá.

Otro material que sí se reconoce en las paredes de algunos sectores de la explotación subterránea es un chert de color gris oscuro con bandas. Su posible explotación se ha estudiado mediante:

- La cartografía geológica de las estructuras mineras para ver qué unidades geológicas siguen, analizar la disposición de los niveles de mineral y compararla con la distribución de las minas (Costa et alii, 1994).

- El estudio de las industrias líticas sobre materiales oscuros de yacimientos contemporáneos y próximos geográficamente, considerando la posibilidad de que su fuente de materia prima fuera Gavá. El trabajo se ha iniciado juntamente con R.M. Senabre y J. Socias, colaboradores del Museo de Vilafranca del Penedés.

En el primer caso, se observa que la traza de las galerías no sigue necesariamente la de las estructuras geológicas que contienen el chert. Por el contrario, aquéllas atraviesan niveles de este mineral, sin presentar frentes de explotación, hasta alcanzar nuevas mineralizaciones de variscita. El segundo estudio se ha centrado por ahora en las industrias postcardiales de la comarca vecina del Penedés, el simple análisis macroscópico de las cuales muestra diferencias patentes con los cherts de Gavá.

A pesar de que las evidencias actuales no demuestran la obtención de corneana o de chert oscuro en las minas neolíticas de Gavà, además de variscita, creemos que aún no puede descartarse la posible obtención de otros minerales y que ésta debe continuar siendo indagada.

T. P., 53, n. ${ }^{\circ} 1,1996$

\section{EL TRABAJO DEL MINERAL: LAS CUENTAS DE VARISCITA (TIPOLOGÍA Y TECNOLOGÍA) (A.E.M y M.J.N.M.)}

Las cuentas de variscita en proceso de elaboración que se han recuperado en la excavación de algunas de las minas nos permiten afirmar con toda certeza que el trabajo del mineral se realizaba en el mismo yacimiento. Ello otorga a las minas un doble papel e importancia, como centro de explotación y de producción al mismo tiempo.

Presentamos ahora aquí los resultados provisionales del estudio de una muestra de 190 cuentas de variscita, provenientes de las minas 68 y 70 (Neolítico Antiguo Postcardial) y de las 16 y 72 (Neolítico Medio).

La distribución de las cuentas es la siguiente:

Mina 68, nivel 5: 1

Mina 70, nivel 8: 1

Mina 16, nivel 2: 24

nivel 4: 1

nivel 5: 5

nivel 6: 118

nivel 7: 12

nivel 8: 27

Mina 72, nivel 1: 1

La muestra es bastante significativa, incluye cuentas y fragmentos de muy reducido tamaño, la recuperación de las cuales ha sido posible gracias a la metodología de excavación empleada: cribado con agua y una malla de $2 \mathrm{~mm}$ de luz de todo el sedimento.

De las cuentas recuperadas 5 están totalmente acabadas $(2,63 \%)$ y $140(73,69 \%)$ en diferentes momentos del proceso de fabricación. Finalmente, hay 45 fragmentos $(23,68 \%)$ con señales de manipulación que podrían ser restos del proceso de elaboración.

No es de extrañar que el número de cuentas rotas sea muy elevado, ya que la variscita tiene poca dureza, de 4 a 5 en la escala de Mohs, y es un material frágil. Por otro lado, el tamaño muy reducido de muchas de ellas debió hacer difícil su manipulación y frecuente su fractura. Incluso los joyeros que trabajan este mineral hoy día con técnicas actuales, pierden una elevada proporción del mineral.

Para el estudio de las cuentas de collar hemos creado una ficha de trabajo que contem- 
pla los siguientes aspectos: número de inventario, color, materia prima, estado de la pieza, fractura y aspectos métricos (diámetro máximo y mínimo de la cuenta y de la perforación, espesor/altura). Dentro del estado de la pieza hay varias posibilidades: enteras con perforación (EP), con inicio de perforación (EIP) y sin perforación (ESP); partidas por la mitad con perforación (PMP), y sin ella (PSP). En otros (OTR) se incluyen aquellos fragmentos con señales claras de haber sido manipulados, pero que por su morfología difícilmente pueden considerarse cuentas. El tipo de perforación atiende a su morfología (cilíndrica, cónica, bicónica) y dirección (bidireccional/unidireccional). Finalmente, un apartado de huellas describe su tipología. La ficha se completa con un croquis de la cuenta y un apartado de observaciones.

La ficha se basa en una observación macroscópica y mediante lupa binocular de $20 \mathrm{X}$ y 40X. Paralelamente, hemos iniciado el análisis de diferentes utensilios relacionados con la fabricación de las cuentas, como son las brocas de sílex y los pulidores de arenisca.

El proceso de elaboración de una cuenta de collar se iniciaba separando la veta de variscita del bloque de pizarra. El fragmento obtenido se trabajaba mediante la talla y/o el pulimento/abrasión para configurar la cuenta. La mayoría de las estudiadas parecen haberlo sido mediante el segundo procedimiento. En el conjunto aparecen nueve ejemplares que no pasaron de este estadio de la cadena operativa, la mayoría discoidales, y sólo algunas cilíndricas y de tonelete. Estas cuentas presentan unas finas estrías lineales paralelas en la mayor parte de los casos, que se aprecian en las dos superficies así como en los bordes. Normalmente, las estrías identificadas en los bordes son perpendiculares a las caras aunque en algunos casos aparecen oblicuas. Algunos ejemplares, a los que ya se les ha iniciado la perforación, presentan unos leves "retoques" producto de la talla, por lo que creemos que ésta podía haber intervenido en algún momento del proceso de fabricación, siendo previa a la abrasión/pulimento.

El siguiente paso sería la perforación. La mayoría de las cuentas recuperadas está partida por la mitad con la perforación ya casi acabada (108). La perforación se realizaba desde las dos caras de la cuenta (se ha podido identificar en 97 casos), era en el momento de unión cuando se fragmentaban, aunque once fragmentos en los que no se aprecia perforación igualmente están partidos por la mitad. Asimismo, hay docé ejemplares en los que la perforación únicamente se ha iniciado desde una o las dos caras. La morfología de las perforaciones resultantes varía siendo en muchos casos bicónica, cónica en otros y, las menos, cilíndricas. Las perforaciones cónicas y bicónicas no implican el uso de un perforador de este tipo. Probablemente todos los perforadores son cilíndricos, obteniéndose la forma cónica por el propio movimiento de rotación, que hace el agujero algo más ancho en superficie que en la parte central de la cuenta. En muchos casos se aprecian finas estrías producto de la rotación del perforador así como un brillo acentuado a su alrededor.

La perforación podría haberse realizado mediante perforadores manuales, que están presentes en la industria lítica del yacimiento, o con instrumentos algo más complejos como los taladros de arco o de disco (Arenas y Bañolas, 1989). Éstos estarían realizados sobre materiales perecederos (madera, fibras vegetales, etc.), y en el extremo se sujetaría la base de la broca o perforador con algún tipo de almáciga, del mismo modo que la cuenta se fijaría a algún soporte para perforarla. De este complejo sistema de perforación hemos recuperado diez brocas, procedentes del relleno de la Mina 16. El proceso de fabricación de las brocas está también representado en el conjunto estudiado. Se elaboraban a partir de pequeñas laminitas de dorso ( 2 brocas) de sección triangular/trapezoidal. Posteriormente, estas laminitas serían regularizadas mediante pulimento. Ocho de ellas presentan la superficie pulida, y con finísimas estrías longitudinales. La sección es prismática o circular, con cuatro ejemplos en cada caso. Los extremos están redondeados, y a veces presentan una débil concavidad. En dos casos parecen facetados/retocados. El grosor de las laminitas de dorso está entre $2 \mathrm{~mm}$. y $4 \mathrm{~mm}$. El diámetro de las brocas oscila entre $1,5 \mathrm{~mm}(2$ ejemplares) y $2 \mathrm{~mm}$. (6 ejemplares). Estas dimensiones se corresponden con los diámetros de las perforaciones estudiadas: diámetro entre 
$1 \mathrm{~mm}$ y $1,9 \mathrm{~mm}, 61$ cuentas $(52,16 \%)$; diámetro entre $2 \mathrm{~mm}$ y $2,99 \mathrm{~mm}, 51$ cuentas $(43,58 \%)$; diámetro $3 \mathrm{~mm}, 3$ cuentas $(2,56 \%)$ y diámetro de $4 \mathrm{~mm}, 2$ cuentas $(1,7 \%)$.

En cuanto al diámetro máximo total hay que señalar que la mayoría de las cuentas $(87,14 \%)$ se mueve entre $5 \mathrm{~mm}$. y $8 \mathrm{~mm}$. Las de mayor tamaño son 4 ejemplares que sobrepasan los $10 \mathrm{~mm}(2,44 \%$ del total) y $5(3,06 \%)$ de $10 \mathrm{~mm}$.

La forma discoidal de la cuenta se obtenía antes de perforarla a pesar de que la perforación era la fase más difícil y delicada del proceso de fabricación. Esto puede ser exigencia del proceso de fabricación. La fijación de las cuentas a un soporte y su perforación es más fácil si todas tienen ya el tamaño y la forma regularizada. Es probable de todas formas que después hubiera un nuevo pulido para perfeccionar la superficie de la cuenta.

Los pulidores conservan, en algunos casos, surcos muy netos, más o menos rectilíneos y de sección más o menos en forma de U. La confirmación de que estos pulidores eran los empleados para configurar las cuentas y no piezas de hueso o piedra, sólo vendrá dada por la analítica.

Llama la atención el hecho de que la práctica totalidad de las cuentas estudiadas sean discoidales (171 cuentas, $90 \%$ frente a 19 cilíndricas $y / 0$ de tonelete $10 \%$ ), mientras que esta tipología es sólo una más entre las presentes en los ajuares de la Cultura de los Sepulcros de Fosa. La mayoría de los datos de estos últimos proviene de excavaciones antiguas (Muñoz, 1965) y es posible que las cuentas de menor tamaño se perdieran, ya que en nuestro caso casi siempre han aparecido en el proceso de criba con agua. De esta forma, su número estaría desequilibrado respecto al de otros tipos de cuentas. Esto no explica, en cualquier caso, por qué en las Minas son tan escasos los restos de cuentas mayores, cilíndricas o de tonelete. Tal vez se deba a que, por su tamaño y forma, estas últimas fueran menos frágiles o a que sus restos se reaprovecharan para realizar más cuentas discoidales.

El hecho de que los restos de fabricación de las cuentas de collar aparezcan como un material de desecho más, incluidos los cinco ejem- plares enteros conservados, en el relleno de las minas, nos lleva a plantear la cuestión de cuál era el valor de la variscita en el Neolítico. ¿Era apreciado el mineral en sí?. El rechazo de los desperdicios de la fabricación de cuentas parece desmentirlo. ¿Cuál era el valor de la variscita en particular para sus explotadores directos?. El hecho de que en sepulturas neolíticas efectuadas en minas abandonadas no aparezca este mineral junto a los restos humanos, ¿es debido a que los mineros no podían acceder a la variscita o a un defecto de la excavación?. Recuérdese que la práctica totalidad de las cuentas estudiadas, ha sido hallada gracias al cribado con agua y malla fina del relleno. ¿Son posibles otras explicaciones relacionadas con su rentabilidad en el intercambio?.

Elementos de adorno, a través de circuitos de distribución todavía no bien conocidos, partieron de Gavá ya elaborados. A. Blasco, M. Edo y M.J. Villalba (1990-1991: 284) proponen tres rutas de difusión: hacia el Norte, el Noroeste y el Sur. Desde Gavá se accede a las vías naturales de comunicación con el resto de Cataluña. Ahora bien, que las perlas más antiguas sean anteriores al inicio de las explotaciones en Gavá y el descubrimiento de otros yacimientos minerales de variscita (Melgarejo, 1992; Camprubí et alii, 1994), impide afirmar que las Minas de Gavá fueron la fuente de la variscita de toda Cataluña.

\section{EL CONTEXTO ECONÓMICO, SOCIAL E IDEOLÓGICO DE LA MINERÍA NEOLÍTICA EN GAVA (J.B.A. y A.E.M.)}

Aun siendo de gran interés paleoetnológico, el aprovisionamiento de materias primas ha tenido una incorporación reciente en la investigación de las sociedades prehistóricas, a diferencia de campos como la cronología, la tipología de los materiales arqueológicos o la economía. Debemos evitar caer en el extremo opuesto de considerar la Arqueología minera un problema exclusivamente tecnológico. El aprovisionamiento de materias primas no puede ser estudiado aislado del resto de los fenómenos económicos y sociales del marco en el que se produjo.

T. P., 53, n. ${ }^{\circ} 1,1996$ 
Ha sido planteada una posible especialización de las comunidades neolíticas de Gavá en la minería que, desde nuestro punto de vista, los vestigios arqueológicos no permiten demostrar. Éstos, por el contrario, sugieren además la práctica de otras actividades.

Los restos faunísticos indican la gestión y explotación de recursos animales con finalidades alimentarias: durante el Neolítico Antiguo Evolucionado una ganadería de ovicaprinos, seguidos por bóvidos y suidos (Saña, 1994: 183) y durante el Neolítico Medio una ganadería bien establecida, fuertemente orientada a la explotación de carne, en la que los bóvidos tendrían una importancia fundamental (Estévez, 1986).

El estudio paleocarpológico ha identificado claramente, si bien en un número escaso, Hordeum vulgare en el Neolítico Antiguo Evolucionado (análisis inédito de $\mathrm{R}$. Buxó recogido en Bosch y Estrada, 1994a: 264 y ss.). En el Neolítico Medio las plantas cultivadas están representadas básicamente por cereales entre los que la cebada (Hordeum vulgare L. y Hordeum vulgare L. var. nudum) tiene el porcentaje más elevado, mientras que la proporción de granos de trigo es inferior: escanda (Triticum monococcum L.), trigo almidón (Triticum dicoccum), y trigo blando (Triticum aestivum s. l.). En menor proporción aparecen las leguminosas (Vicia sp.) (Gerhild KrauB-Kashani en Villalba et alii, 1986: 161 y ss.; Buxó et alii 1991: 67 y ss.).

Los primeros análisis palinológicos en el yacimiento mostraron ya una abundante presencia de gramíneas, de las cuales más de la mitad era cultivada. Corrobora la práctica agrícola la asociación Rumex-Plantago-Cyperaceae (Yll, 1987: 17-18). Significativos para la identificación de una actividad agrícola en Gavá durante el Neolítico Medio, han sido también los análisis palinológicos posteriores efectuados por S. Riera (1). Destacamos el alto porcentage observado de Cerealia, la presencia de numerosos grumos polínicos de este taxon, evidencia de

(1) S. Riera (1995): "Informe sobre l'anàlisi pol. línica de mostres obtingudes a la mina 16 de Can Tintorer (Gavà, Baix Llobregat)", treball inèdit del Servei C-T de Gestió $\mathrm{i}$ Evolució del Paisatge, Universitat de Barcelona. que o bien los campos de cereal estaban muy cerca del yacimiento, o bien fueron tirados en la mina restos de cultivo cerealístico. Existen, por otro lado, numerosos táxones herbáceos que corresponden a plantas ruderales y adventicias, las cuales ponen de manifiesto la existencia de suelos perturbados y nitrificados debido a actividades humanas, que pudieron ser tanto agrícolas como pecuarias.

Los estudios malacológicos constatan la recolección de especies malacológicas marinas con finalidades alimentarias, junto a otras de uso quizás únicamente ornamental (Oller, 1986: 185 y ss.; Estrada y Nadal, 1994: 188).

La localización del área minera explotada sugiere también otras actividades además de la minera. En la actualidad, las estructuras mineras neolíticas están concentradas en la elevación o cerro de Can Tintorer; mientras que el área explotable desde el punto de vista geológico (afloramiento paleozoico en la vertiente norte del Garraf) supera sobradamente la superficie de dicho cerro. Se desconocen las causas de esta distribución de la explotación. Proponemos como hipótesis la elección de su ubicación no sólo en función de la riqueza mineral del subsuelo, sino también de la proximidad a medios ecológicos diversos que proporcionasen una complementariedad de recursos cerca del asentamiento: llano litoral, línea de costa, marismas, mar y montaña.

La agricultura y la ganadería en el litoral del llano de Barcelona, contemporáneamente al funcionamiento de las minas de Gavá, están constatadas por diagramas polínicos y de cenizas obtenidos por sondeos en diferentes puntos del mismo (Riera, 1994: 206-208). En un marco de robledales mezclados con encinares y pinares se documentan, en una cronología anterior al 3150 a.C. (no cal.), las primeras modificaciones humanas del medio vegetal: deforestaciones de cierta extensión consecuencia de incendios provocados, clareos temporales y espacialmente irregulares localizados en áreas próximas al litoral, como demuestran los altos valores de macrocenizas registrados. En estas zonas los sistemas forestales debían ser por naturaleza más frágiles, al ser zonas marginales del bosque donde se debieron llevar a término con mayor facilidad las primeras actividades 
productoras. Durante estas fases de perturbación forestal los arbustos se expandieron, así como numerosos táxones ruderales y nitrófilos que pueden relacionarse con la existencia de prados húmedos nitrificados, muy probablemente por la presencia de rebaños. Por otro lado, comienzan a estar presentes los táxones secundarios indicadores de actividad agrícola, paralelamente al incremento sustancial de los valores del taxón Cerealia, si bien en sectores litorales este taxon incluye también especies silvestres.

Finalmente, tampoco creemos que comporte una especialización el trabajo requerido para la explotación de las minas. La experimentación no nos permite calcular aún de forma satisfactoria el tiempo que costaría excavar un tramo determinado de mina en la litología de Gavá con herramientas copiadas de las neolíticas. A modo de aproximación podemos utilizar los datos estimados por G. Clark para las minas neolíticas de Grime's Graves (Norfolk, Inglaterra): tres hombres durante seis meses abrirían un pozo de $140 \mathrm{~m}^{3}$ (citado en Nougier, 1977: 106). Según estos datos una mina tipo del Neolítico Antiguo Evolucionado de Gavá, que representa un volumen aproximado de $6,14 \mathrm{~m} 3$ de roca, pudo ser explotada en 8 días. Evidentemente, estas cifras sólo son aproximativas, pero revelan que el tiempo necesario para el trabajo minero no parece requerir una especialización.

Los problemas simbólicos y/o "religiosos" que pudieron estar ligados a una explotación minera cuentan con un reducido espacio dentro de la Arqueología minera por las restricciones que impone a su estudio el registro. Los indicadores arqueológicos directos son escasos: grafitos de Krzemionki, y estatuillas de Grimes Graves y Petit Spiennes (Lernia y Galiberti, 1993: 80). Por ello, el hallazgo de una figurilla de cerámica, representando muy probablemente una diosa de la fertilidad, en una de las Minas de Gavá, tiene un gran significado. Algunos de nosotros (Bosch y Estrada, 1994b: 157) expresábamos la hipótesis que la fertilidad a la que debió estar vinculada no fuera únicamente la agrícola, sino que ésta hubiera que entenderla en un sentido más amplio incluyendo también la fertilidad mineral de la tierra. Reco- gíamos el paralelo arqueológico de Grimes Graves, interpretado en un sentido parecido (Green, 1993); y el etnológico de los mineros quechuas bolivianos, que practicaban, como los agricultores, un culto a la diosa Pacha Mama (madre tierra). El mundo simbólico y religioso ligado a la minería debía sin duda ser tan complejo como difícil de llegar a ser conocido hoy; el estudio detallado de objetos como la figura antropomorfa de Gavá y de su contexto arqueológico quizás nos permitirá acercarnos a él.

\section{BIBLIOGRAFÍA}

Álvarez, A. (1993): “Tipologia petrogràfica de les destrals polides de Catalunya”. Empúries, 48-50, I: 18-25.

ÁlvareZ, A. Y CloP, X. (1994): Estudi petrogràfic de la indústria lítica $i$ del macroutillatge lític. En J. Bosch y A. Estrada (1994a): 231-254.

Blasco, A; Edo, M. y Villalba, M.J. (1990-91): "Les perles en Callaïs du Sud de la France proviennent-elles des Mines de Can Tintorer?". Le Chalcolithique en Languedoc, ses relations extra-regionales (Saint-Mathieu-de-Tréviers, 1990), Archéologie en Languedoc. Colloque International Hommage au Dr. Jean Arnal. Conseil Général de l'Herault: 279-289.

Blasco, A.; Villalba, M.J. y Edo, M. (1992): “Cronologia del complex miner de Can Tintorer. Aportacions a la periodització del neolític mitjà català". 9è Col.loqui Internacional d'Arqueologia de Puigcerdà. Estat de la investigació sobre el neolític a Catalunya (Puigcerdà i Andorra, 1991). Institut d'Estudis Ceretans. Andorra: 215-219.

Bosch, A. (1984): "Les destrals polides del nord de Catalunya: tipologia i petrologia". Fonaments, 4: 221-245.

Bosch, J. y EstradA, A. (1994)a: "El Neolític Postcardial a les Mines Prehistòriques de Gavà (Baix Llobregat)". Rubricatum, 0. Revista del Museu de Gavà.

- (1994)b: "La Venus de Gavà (Barcelona). Una aportación fundamental para el estudio de la religión neolítica del suroeste europeo". Trabajos de Prehistoria, 51, 2: $149-158$

Buxó, R.; CATAlÀ, M.y Villaba, M.J. (1991): "Llavors i fruits en un conjunt funerari situat a la galeria d'accés a la mina 28 del complex miner de Can Tintorer (Gavà)". Cypsela, IX: 65-72.

Camprubí, A.; Costa, F. y Melgarejo, J.C. (1994): “Mineralizaciones de fosfatos férrico-alumínicos de Gavà (Catalunya): tipología". Boletín Geológico y Minero, 105-5: 26-35.

Costa, F.; Camprubí, A. y Melgarejo, J.C. (1994): "Aproximación geológica a las minas neolíticas de fosfatos férrico-alumínicos de Gavà (Catalunya)". Boletín Geológico y Minero, 105-5: 436-443.

Estévez, J. (1986): "Estudi de la fauna". En M.J. Villalba et alii: $171-184$.

T. P., 53, n. ${ }^{\circ} 1,1996$ 
EstradA, A. Y NADAL, J. (1994): Les restes malacològiques d'origen marí. En J. Bosch y A. Estrada (1994a): 186-189.

Galiberti, A. y Guarascio, M. (1990): "La mine néolithique de la Defensola (Pouilles- Italie)". En M.R. Séronie-Vivien y M. Lenoir (dir.): Le silex de sa genèse à l'outil. Actes du $\mathrm{V}^{\circ}$ Colloque International sur les silex (Bordeaux, 1987). Cahiers du Quaternaire, 17. Centre National de la Recherche Scientifique. Paris. Vol I: 299-305.

GreEn, B. (1993): Grime's Graves. Norfolk. English Heritage. Londres.

LERNIA, S. Di y GALIBERTI, A. (1993): Archeologia mineraria della selce nella preistoria. Definizioni, potenzialità e prospettive della ricerca. Quaderni del Dipartimento di archeologia e storia delle arti sezione archeologica. Università di Siena, Edizioni all'Insegna del Giglio. Firenze.

Llongueras, M.; Marcet, R. y Petit, M.A. (1981): "Ceràmica de tipus "Chassey" a Catalunya". En El Neolític a Catalunya, Taula Rodona de Montserrat. (1980). Publicaciones de la Abadía de Montserrat. Montserrat: 185-193.

Mata, J.M.; Plana, F. y Traveria, A. (1983): "Estudio mineralógico del yacimiento de fosfatos de Gavá". Boletín Sociedad Española de Mineralogía, 7: 257-258.

Melgarejo, J.C. (1992): Estudio geológico y metalogenético del Paleozoico del Sur de las Cordilleras Costeras Catalanas. Memorias ITGE, 103.

Mestres, J. (1981): "El Neolític Antic Evolucionat Postcardial al Penedès". En El Neolític a Catalunya, Taula Rodona de Montserrat (marzo de 1980). Publicaciones de la Abadía de Montserrat. Montserrat: 103-112.

MuÑoz, A.M. (1965): La cultura neolítica catalana de los "Sepulcros de Fosa". Publicaciones eventuales del Instituto de Arqueología y Prehistoria. Universidad de Barcelona, Barcelona.
Nougier, L.R. (1977): L'économie préhistorique. Col. Que sais-je?. Presses Universitaires de France. Paris.

Olive, M. Y TABORIN, Y. (dir.) (1989): Nature et fonction des foyers préhistoriques. Actes du Colloque International de Nemours, 1987. Memoires du Musée de Préhistoire d'Ille de France, 2.

OlLER, J. (1986): Estudi malacològic. En M. J. Villalba et alii: $185-187$.

Ramos, A. (1984): "La identificación de las fuentes de suministro de un asentamiento prehistórico. El abastecimiento de rocas silíceas para manufacturas talladas". Arqueología Espacial 1. Coloquio sobre distribución y relaciones entre los asentamientos. Teruel: 107-134.

RIERA, S. (1994): Paleobiogeografia, perturbacions $i$ acció antròpica durant l'holocè mitjà al delta del riu Llobregat: l'anàlisi pol.línica del sondatge Mercabarna (MBA). En J. Bosch y A. Estrada (1994a): 195214.

RIPOLL, E. Y LlONGUERAS, M. (1963): "La cultura neolítica de los sepulcros de fosa en Cataluña". Ampurias, XXV: $1-90$.

Ros, M.T. (1986): Anàlisi antracològica, En M.J. Villalba et alii: $167-170$.

- (1994): Anàlisi antracològica de les mines 68 i 70. En J. Bosch y A. Estrada (1994a): 214-218.

SAÑA, M. (1994): Gestió i explotació de recursos faunístics (macrofauna). En J. Bosch y A. Estrada (1994a): 179185.

Villalba, M.J.; Bañolas, L.; Arenas, J. y Alonso, M. (1986): Les mines neolítiques de can Tintorer. Gavà. Excavacions 1978-1980. Excavacions Arqueològiques a Catalunya. Departament de Cultura Generalitat de Catalunya. Barcelona.

YLL, E.I. (1987): "Arqueologia i Palinologia en el Llevant peninsular durant el Tardiglacial i Postglacial". Cypsela, VI: $15-21$. 